\title{
Perspective from Antiquity to the Present
}

\author{
Kim H. Veltman \\ Scientific Director \\ Virtual Maastrict McLuhan Institute \\ (VMMI) \\ The Netherlands \\ http://www.sumscorp.com/cv/ \\ kim_veltman@hotmail.com
}

\section{SYNOPSIS}

Links between optics and representation go back at least to Antiquity. Greco-Roman efforts were linked with scenography (skaenographia). This resulted in a sense of depth usually through convergence along an axis of points (fish-bone perspective) and occasionally towards a central vanishing point. Fictive columns were typically used to close a visual space within a distance of less than 50 meters. Although seemingly realistic, it was linked with imitation: with narratives, rather than with physical reality.

While the mediaeval period largely abandoned geometrical depiction of pictorial space, it introduced a series of projection methods for systematic representation of space, notably, planisphere and astrolabe projections, as well as experimenting with the effects of camera obscuras. Such projections were a starting point of late $14^{\text {th }}$ century scholars such as Prosdocimo da Beldomandi at Padua.

Renaissance perspective, while vaunted to be a rebirth of ancient methods, transformed its methods and goals, from imitation of general things to matching of specific objects. Brunelleschi's first demonstrations using the Baptistery of San Giovanni and the Piazza dell Signoria in Florence are famous examples. Paradoxically, this did not lead immediately to a copying of the natural world. In Florence, the method was applied primarily to marquetry (intarsia) typically entailing regular solids, musical instruments and some idealised scenes. In the $16^{\text {th }}$ century, when the method spread to Germany, Nürnberg goldsmiths and jewelers were particularly enthusiastic about depicting regular and semi-regular shapes. By contrast, French, Belgian and Netherlandish artists depicted ruins and idealised buildings.
One of the unforeseen consequences was the development of views (vedute). Some were effectively topographical studies in the manner of surveyor's maps and pictures. These led to neoClassical art, with seemingly realistic architecture. Others were completely fictive (capriccios). Some, such as Ruisdael's landscapes of Norwegian waterfalls convincingly depicted places he/they had never visited. Others, such as Turner's paintings, showed events in ancient Carthage or Rome at which he could not possibly have been present. Indeed, this led to a whole school of Romanticism, which took man to the peaks of mountains, the centre of storms and other places of danger at the limits of the imaginable.

Piero della Francesca and Leonardo da Vinci were among the pioneers in exploring anamorphic effects, cases where extreme positions of a picture plane relative to objects caused dramatic distortions. Leonardo was also one of the early artists to explore the effects of applying the new method to cylindrical and spherical surfaces. In the $16^{\text {th }}$ century, this was further explored by Carlo d'Urbino and Cigoli. In the $17^{\text {th }}$ century, this theme became a regular feature of printed books: e.g., Dubreuil, 1642-1649 and Abraham Bosse, 1648. One reaction was to avoid near distance cases where distortion was extreme. This led to a narrowing of the field of vision.

Meanwhile, the eighteenth century increasingly applied perspective to gardens, and large spaces stretching as far as the horizon. Some spaces were calculated to make distances look closer, others to make it look further away. Space became something to be manipulated: the eye a sense to be tricked. This often led to a widening of the field of vision, and occasionally to a narrow peephole as 
in Piranesi's gate of Knights of Malta in the Santa Sabina hill in Rome.

The $19^{\text {th }}$ century saw new attention to properties of geometry and optics. Von Helmholtz explored the possibility that optical space within the retina might entail Riemannian rather than Euclidean space. In the latter $19^{\text {th }}$ century, theoreticians such as Herdman (1863) outlined possibilities of (cylindrical) curvilinear perspective.

Rhetorically, there has been an attack on perspective in the $20^{\text {th }}$ century, to the extent that some have spoken of the death of perspective. In practice, there have been more publications than ever, along with a radical increase in alternative methods. Jobin (1932) was interested in curvilinear methods in connection with skyscrapers. Barre \& Flocon (1967) were interested in where it corresponded to perception of the eye. Painters such as Termes have compared 1, 2, 3, 4, 5, and 6 -point perspective on spheres. Architects such as Correia (2015) and Correia et al. (2015) have developed software that allows users to go from linear to cylindrical and spherical perspective as part of a spectrum of choices.

Solutions include a simple perspectival machine by the twins Ryan and Trevor Oakes (2011). More fundamental is the work of Paul Debevec (1996 \& 1998), whose reflection mapping has led to new ways to record both real and fictive spaces and whose light stage includes a total-surround solution to recreation of spaces, which is being adapted in the field of virtual actors to bring no longer living actors back to the life on the stage. The lecture will show that the recent interest of the POV (Persistence of Vision) group in Britain relates to a richer tradition than might be immediately apparent.

\section{ACKNOWLEDGMENTS}

This essay represents a brief excerpt from the author's Sources and Literature of Perspective (six volumes, in press). Figure 1 is from volume 2, $\mathrm{p}$. 341.

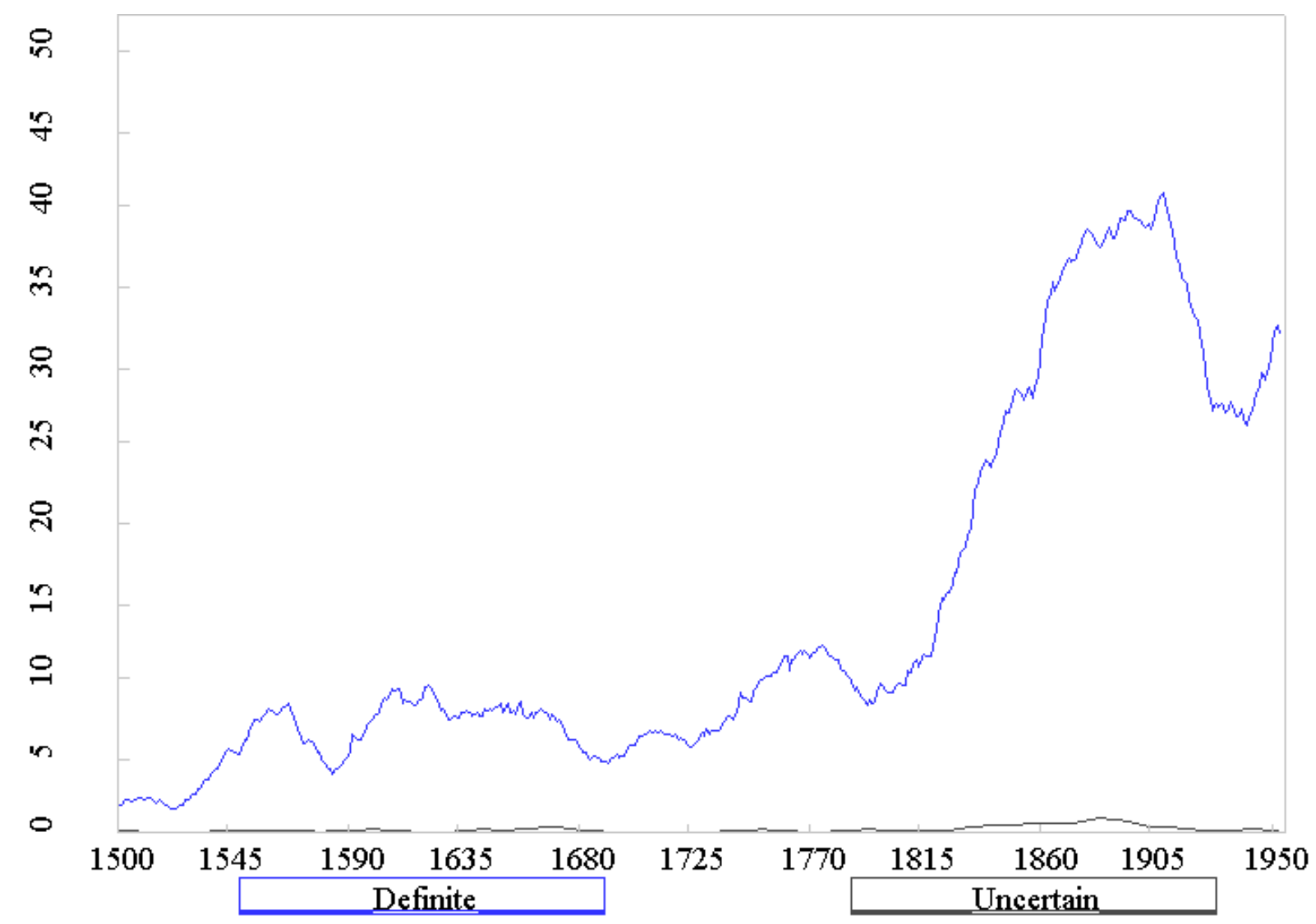

Figure 1: Graph of publications on perspective (number of books on the $y$-axis and corresponding years on the $x$-axis). 


\section{REFERENCES}

Barre, A. and Flocon, A. (1967) Perspective Curviligne: De l'espace visuel a l'image construite. Paris: Flammarion.

Correia, J. V. de A. F. (2015) Perspectiva linear paramétrica: um sistema híbrido de representação perspéctica, aplicável à arquitectura. University of Lisbon, Portugal.

https://www.repository.utl.pt/bitstream/10400.5/117 33/3/Tese $\% 20$ Doutoramento $\% 20-\% 20 J V C \% 20$ \%20Fevereiro\%202015.pdf (accessed 11 May 2017).

Correia, J. V., da Costa, M. C., Guerreiro, A. S., and Romão, L. (2015), Eyesight cartographies unfolding the visual sphere. Journal for Geometry and Graphics, 19(1), pp. 117-130. http://naadir.fa.ulisboa.pt/2015 JGG EC.pdf (accessed 11May 2017).

Debevec, P. (1996) Modeling and rendering architecture from photographs: a hybrid geometryand image-based approach. Proc. 23rd Annual
Conference on Computer Graphics and Interactive Techniques, pp. 11-20.

Debevec, P. (1998) Rendering synthetic objects into real scenes: Bridging traditional and imagebased graphics with global illumination and dynamic range photography. Proc. SIGGRAPH 98 Conference, July. http://www.pauldebevec.com/Research/lBL/debeve c-siggraph98.pdf (accessed 11 May 2017).

Herdman, W. G. (1863) A Treatise on the Curvilinear Perspective and its Applicability to Art. London. Reprint: Nabu Press (2011).

Jobin, I. (1932) Ligne Droite ou Ligne Courbe? Cône ou sphère optique, nouvelles théories de perspective artistique. Montreal: Editions Albert Lévesque.

Oakes, R. and Oakes, T. (2009) Invention reported by: Jobson, C. (2011) 3D Drawing Machine.

Colossal, New York, 11 September.

http://www.thisiscolossal.com/2011/09/3d-drawingmachine/ (accessed 11 May 2017). 